(c) American Dairy Science Association, 2007.

\title{
Relationship Between Antimicrobial Drug Usage and Antimicrobial Susceptibility of Gram-Positive Mastitis Pathogens
}

\author{
M. Pol and P. L. Ruegg ${ }^{1}$ \\ Department of Dairy Science, University of Wisconsin, Madison 53706
}

\section{ABSTRACT}

The objective of this study was to analyze relationships between usage of antimicrobial drugs on dairy farms and results of antimicrobial susceptibility testing of mastitis pathogens. Exposure to selected antimicrobial drugs $(\mathrm{n}=10)$ was standardized by calculation of the number of defined daily doses used per cow. Farms $(n=40)$ were categorized based on amount of antimicrobial exposure: organic (no usage); conventional-low usage (conventional farms not using or using less than or equal to the first quartile of use of each compound); and conventional-high usage (conventional farms using more than the first quartile of a particular compound). The minimum inhibitory concentration (MIC) of selected antimicrobial drugs was determined using a commercial microbroth dilution system for isolates of Staphylococcus aureus $(\mathrm{n}=137)$, coagulase-negative staphylococci (CNS, n = 294), and Streptococcus spp. ( $\mathrm{n}=95$ ) obtained from subclinical mastitis infections. Most isolates were inhibited at the lowest dilution tested of most antimicrobial drugs. Survival curves for Staph. aureus and CNS demonstrated heterogeneity in MIC based on the amount of exposure to penicillin and pirlimycin. For CNS, farm type was associated with the MIC of ampicillin and tetracycline. For Streptococcus spp., farm type was associated with MIC of pirlimycin and tetracycline. For all mastitis pathogens studied, the MIC of pirlimycin increased with increasing exposure to defined daily doses of pirlimycin. The level of exposure to most other antimicrobial drugs was not associated with MIC of mastitis pathogens. A dose-response effect between antimicrobial exposure and susceptibility was observed for some pathogen-antimicrobial combinations, but exposure to other antimicrobial drugs commonly used for prevention and treatment of mastitis was not associated with resistance.

Key words: dairy, resistance, antibiotic, mastitis

Received May 10, 2006.

Accepted August 7, 2006.

${ }^{1}$ Corresponding author: plruegg@wisc.edu

\section{INTRODUCTION}

Mastitis is one of the most frequent infectious diseases in dairy cattle and is the primary cause of antimicrobial drug usage in adult dairy cows (Pol and Ruegg, 2007). Staphylococcus aureus, Streptococcus spp., CNS, and coliforms are commonly isolated from IMI. Lactating cows may be treated for mastitis when they exhibit clinical symptoms or when there is evidence of subclinical infection. In the United States, a limited number of antimicrobial drug groups are available for intramammary treatment of mastitis including $\beta$-lactams (penicillin, cephapirin, ceftiofur, amoxicillin, hetacillin, and cloxacillin), macrolides (erythromycin), coumarines (novobiocin), and lincosamides (pirlimycin) (FDA-Center for Veterinary Medicine, 2004). Intramammary infections of lactating or nonlactating cows are sometimes treated using parenteral compounds (Gruet et al., 2001). The administration of longer acting antibiotic preparations to nonlactating cows is highly adopted and is an essential component of most mastitis control programs (Smith et al., 1966).

Antimicrobial drugs are used in mature dairy cattle to treat clinically and subclinically diseased animals, and to prevent disease in healthy animals (Aarestrup, 2005). Antimicrobial drugs are not administered on all dairy farms. According to national organic standards (USDA National Organic Program, 2002), animals producing organic products may not receive antibiotics for any reason. Producers cannot withhold treatment from a sick animal, but if organically raised animals receive antimicrobial drugs, no products (such as meat or milk) from that animal may ever be sold as organic. It was suggested that the usage of antimicrobial drugs in food animals might affect human health by increasing the risk of antimicrobial residues or by influencing the generation or selection of drug-resistant foodborne pathogens (Yan and Gilbert, 2004). Consumers are increasingly concerned about the use of antimicrobial drugs in food animals, particularly about the use of subtherapeutic doses as growth promoters (Cox and Popken, 2004). In dairy cows, monensin is the only compound that may be used in this manner, but the use of longacting therapeutic doses of antibiotics administered at dry-off is widespread. Antimicrobial drug susceptibility 
was analyzed for bacteria isolated from milk of cows located on farms with potentially different levels of exposure to antimicrobial drugs (Tikofsky et al., 2003; Rajala-Schultz et al., 2004). Tikofsky et al. (2003) used results of agar disk diffusions to determine that a greater proportion of Staph. aureus isolated from mastitis cases occurring on organic farms were susceptible to some $\beta$-lactam antibiotics compared with isolates obtained from conventional herds. Rajala-Schultz et al. (2004) studied susceptibility of CNS isolated from milk samples obtained from primiparous and multiparous cows located on a single farm in Ohio. The authors hypothesized that primiparous cows may have had fewer opportunities for exposure to antimicrobial drugs compared with older cows, but failed to detect statistically significant differences based on parity.

The previously described studies have contributed to our understanding of possible relationships between antimicrobial usage and bacterial resistance in dairy cattle, but none have quantified antimicrobial usage at the farm or cow level. The objective of this study was to analyze the relationships between a standardized measure of antimicrobial exposure on dairy farms and results of susceptibility testing of a variety of mastitis pathogens.

\section{MATERIALS AND METHODS}

\section{Herd Selection}

Commercial organic (ORG; $\mathrm{n}=20)$ and conventional $(\mathbf{C O N} ; \mathrm{n}=20)$ farms were selected as described in the companion article (Pol and Ruegg, 2007). In brief, farmers were recruited by personal contact or from a preexisting mailing list. Enrollment criteria required herds to have a 6 -mo average bulk tank SCC $\geq 250,000$ cells/ $\mathrm{mL}$. Additionally, CON farms were required to have used comprehensive antimicrobial dry-cow therapy (DCT) for at least $5 \mathrm{yr}$. Organic farms were required to be certified organic for at least $3 \mathrm{yr}$.

\section{Estimation of Antimicrobial Exposure}

Antimicrobial exposure was estimated using an 84question survey instrument as described separately (Pol and Ruegg, 2007). Information collected included dose, frequency, duration of treatment, and annual prevalence of treatment. Antimicrobial drug usage was estimated for: amoxicillin, ampicillin, ceftiofur, cephapirin, cloxacillin, erythromycin, novobiocin, penicillin, pirlimycin, sulfadimethoxine, and tetracycline. Usage of amoxicillin and ampicillin were combined and analyzed together. Likewise, closely related antimicrobial drugs (such as oxytetracycline and chlortetracycline) were combined and analyzed together. Antimicrobial usage was standardized using a defined daily dose (DDD) as described in the companion article ( $\mathrm{Pol}$ and Ruegg, 2007). In brief, the DDD is the maximum dose a standard animal (BW $=680 \mathrm{~kg}$ ) would receive if it were treated following the FDA-approved label dosages. For each farm, the number of DDD used at farm level was calculated by dividing the reported total dose (mg or IU) of each drug used per year by the DDD of that antimicrobial drug. The number of DDD was divided by the total number of milking cows to estimate the density of use of the antimicrobial drug. Antimicrobial drug usage density was expressed as number of DDD per lactating cow per year.

The density of use was expressed as number of DDD used per cow (lactating and nonlactating) per year. The total exposure to antimicrobial drugs was estimated per farm per year for treatment of selected diseases. Farms were categorized into 1 of 3 usage groups based on density of antimicrobial drug usage for each drug studied: 1) Organic farms: no use of antimicrobial drugs $(\mathrm{n}=20)$; 2) Conventional farms, low exposure (CON$\mathbf{L} ; \mathrm{n}=15)$ : no use of the studied antimicrobial drug or used less DDD than the 5 farms with the highest number of DDD; and 3) Conventional farms, high exposure $(\mathbf{C O N}-\mathbf{H} ; \mathrm{n}=5)$ : the 5 farms that reported the highest DDD for each compound among the studied farms.

\section{Collection of Milk Samples}

Quarter milk samples were obtained from a maximum of 50 multiparous cows that had no signs of clinical mastitis during a single visit to each farm. Only multiparous cows were sampled to ensure that at least 1 known exposure to intramammary antimicrobial drugs (DCT) had occurred for all sampled animals. On farms with less than 50 multiparous cows, all multiparous cows were sampled. On farms with more than 50 multiparous cows, convenience sampling was performed (i.e., milk samples were obtained from available multiparous cows during milking). On $3 \mathrm{CON}$ farms, sampled cows were selected because they had a previous testday SCC $>250,000$ cells $/ \mathrm{mL}$. Quarter foremilk samples were collected by study personnel at milking using standard aseptic technique. Milk samples were immediately cooled and transported to the laboratory. If bacteriological analysis could not to be performed within $24 \mathrm{~h}$, samples were frozen for up to $2 \mathrm{wk}$ before processing.

\section{Bacteriological Culture and Susceptibility Tests}

With the exception of the initial inoculum volume, microbiologic procedures were performed as outlined by the National Mastitis Council (1999). In brief, 0.10 $\mathrm{mL}$ of each milk sample was streaked on one half of a 
blood agar plate, and plates were incubated at $37^{\circ} \mathrm{C}$ for 24 to $48 \mathrm{~h}$. Morphology and hemolysis pattern of a colony picked from plates with $\geq 3 \mathrm{cfu}$ were determined, and organisms were differentiated by means of standard microbiologic methods (National Mastitis Council, 1999). In particular, Staph. aureus was differentiated from other staphylococci by means of mannitol and tube coagulase reactions. Streptococcus spp. were identified with the CAMP test and esculin reaction. Gram-negative bacteria were identified using MacConkey agar, motility, indole, and ornithine reactions and growth on triple sugar iron slants. Definite identification of grampositive bacteria suspected of belonging to the genera Staphylococcus or Streptococcus was performed using a miniaturized identification method (BBL Crystal, Becton Dickinson Microbiology Systems, Franklin Lakes, NJ). Only isolates yielding identification with confidence intervals greater than 0.75 were included for analysis. Milk samples that contained $\geq 3$ dissimilar colony types were considered contaminated.

Antimicrobial susceptibility was evaluated for isolates confirmed as: Staph. aureus, CNS, and Strep. spp. (except Strep. agalactiae). For both CON and ORG herds, a similar variety of CNS species were included in susceptibility testing. The majority of streptococci included in susceptibility testing were Streptococcus uberis and Streptococcus dysgalactiae; no isolates identified as enterococci were included in the susceptibility testing. Antimicrobial susceptibility was tested using the mastitis panel of a commercial broth microdilution test (Sensititre, TREK Diagnostics, Cleveland, OH) following guidelines of the Clinical and Laboratory Standards Institute (formerly NCCLS). In brief, bacterial suspensions used for inoculation of microdilution plates were standardized to a $0.5 \mathrm{McF}$ arland standard per manufacturer instructions. Aliquots $(50 \mu \mathrm{L})$ were dispensed into each well on the microdilution plates, and plates were incubated aerobically at 35 to $37^{\circ} \mathrm{C}$ for 18 to $24 \mathrm{~h}$. Antimicrobial drugs tested were ampicillin, ceftiofur, cephalothin, erythromycin, oxacillin $+2 \%$ $\mathrm{NaCl}$, penicillin, penicillin/novobiocin, pirlimycin, sulfadimethoxine, and tetracycline. Quality control organisms included Staph. aureus [American Type Culture Collection (ATCC) 29213], Enterococcus faecalis (ATCC 29212), Escherichia coli (ATCC 25922), and Pseudomonas aeruginosa (ATCC 27853) in accordance to the recommendations (Clinical and Laboratory Standards Institute, 2002).

\section{Statistical Analysis}

The PROC FREQ (SAS Institute, 2003) was used to perform $\chi^{2}$ analysis to determine if the proportion of each type of pathogen isolated was independent of herd type (CON vs. ORG) for the given species of bacteria. In each test, herd type formed the rows of the table. The positive or negative results of culture (no growth, CNS, Strep. spp., Staph. aureus, coliforms, Strep. agalactiae, other isolates, or contaminated) formed the columns of the tables of each of the 8 tests performed.

The PROC FREQ procedure (SAS Institute, 2003) was used to perform $\chi^{2}$ analysis to determine if the MIC was independent of herd type (CON vs. ORG). In each test, herd type formed the rows of the table. The antimicrobial drug concentrations present in wells of the panel of the susceptibility test for each of the 10 antimicrobial drugs tested in each of the 3 bacterial groups studied (Staph. aureus, CNS, or Strep. spp.) formed the columns of the tables of each of the 30 tests (10 per type of isolate).

The PROC FREQ (SAS Institute, 2003) was used to perform $\chi^{2}$ analysis to determine if the proportion of susceptible isolates was independent of herd type (CON vs. ORG). In each test, herd type formed the rows of the table. Susceptibility outcomes were placed into 2 categories that formed the columns: susceptible and resistant. The resistant category included those isolates categorized as either intermediate or resistant. The odds of resistance based on herd type were calculated by dividing the odds of resistance for $\mathrm{CON}$ herds by the odds of resistance for ORG herds. When expected values were less than 5 in more than $20 \%$ of the cells the Fisher's exact test was used.

The PROC LIFETEST of SAS (SAS Institute, 2003) was used to perform survival analysis of isolates based on antimicrobial usage category (ORG, CON-L, or CON$\mathrm{H})$. The antimicrobial concentrations present in wells of the panel of the susceptibility test were used as "time" in the survival analysis. The event was defined as inhibition of bacterial growth, and isolates that presented growth at the highest tested concentration were censored. Kaplan-Meier survival curves of the antimicrobial usage groups were produced for each of the isolateantimicrobial drugs combinations studied. The null hypothesis of no differences in the survivor functions of the strata (antimicrobial usage groups) was evaluated using Log-Rank and Wilcoxon tests. Both statistics test the same null hypothesis (i.e., no difference among the groups), but they differ in their sensitivity to various kinds of departures from that hypothesis. The Wilcoxon test is less sensitive than the Log-Rank to differences in the groups that occur at later points in time (higher MIC).

Statistical significance was set at a $P$-value $<0.05$.

For each farm and isolate type, isolates included in statistical analysis were randomly selected. Moreover, only 1 isolate per cow and no more than 20 isolates per 
Table 1. Descriptive statistics of number of defined daily doses (DDD) for total use (all studied diseases and all routes) of selected antimicrobial drugs used on conventional farms

\begin{tabular}{|c|c|c|c|c|c|c|c|c|}
\hline \multirow[b]{2}{*}{ Drug } & \multirow[b]{2}{*}{ Route } & \multirow[b]{2}{*}{ Herds (n) } & \multicolumn{6}{|c|}{ Number of DDD per cow per year } \\
\hline & & & Mean & SEM & $\mathrm{Q} 1^{1}$ & Median & Minimum & Maximum \\
\hline \multirow[t]{2}{*}{ Ceftiofur } & Parenteral & 20 & 0.58 & 0.16 & 0.17 & 0.31 & 0.03 & 2.48 \\
\hline & Intramammary & $1^{2}$ & 17.7 & & & & & \\
\hline \multirow[t]{2}{*}{ Cephapirin } & Parenteral & 0 & & & & & & \\
\hline & Intramammary & 20 & 1.59 & 0.50 & 0.77 & 0.86 & 0.04 & 10.39 \\
\hline \multirow[t]{2}{*}{ Penicillin } & Parenteral & 15 & 0.65 & 0.30 & 0.13 & 0.25 & 0.09 & 4.21 \\
\hline & Intramammary & 18 & 0.63 & 0.08 & 0.3 & 0.66 & 0.03 & 1.0 \\
\hline \multirow[t]{2}{*}{ Tetracycline } & Parenteral & 17 & 0.23 & 0.10 & 0.04 & 0.11 & 0.01 & 1.77 \\
\hline & Intramammary & 0 & & & & & & \\
\hline \multirow[t]{2}{*}{ Pirlimycin } & Parenteral & 0 & & & & & & \\
\hline & Intramammary & 15 & 0.70 & 0.25 & 0.11 & 0.26 & 0.01 & 74 \\
\hline \multirow[t]{2}{*}{ Ampicillin } & Parenteral & 13 & 0.04 & 0.02 & $<0.01$ & 0.01 & $<0.01$ & 0.23 \\
\hline & Intramammary $^{3}$ & 8 & 0.66 & 0.28 & 0.23 & 0.26 & 0.15 & 1.97 \\
\hline \multirow[t]{2}{*}{ Sulfadimethoxine } & Parenteral & 7 & 1.60 & 0.78 & 0.31 & 0.63 & 0.01 & 5.33 \\
\hline & Intramammary & 0 & & & & & & \\
\hline \multirow[t]{2}{*}{ Novobiocin } & Parenteral & 0 & & & & & & \\
\hline & Intramammary & 3 & 0.22 & 0.12 & 0.11 & 0.19 & 0.02 & 0.44 \\
\hline \multirow[t]{2}{*}{ Erythromycin } & Parenteral & 0 & & & & & & \\
\hline & Intramammary & 2 & 0.08 & 0.08 & 0.04 & 0.08 & $<0.01$ & 0.16 \\
\hline \multirow[t]{2}{*}{ Cloxacillin } & Parenteral & 0 & & & & & & \\
\hline & Intramammary & 2 & 0.32 & 0.27 & 0.19 & 0.32 & 0.05 & 0.59 \\
\hline
\end{tabular}

${ }^{1} \mathrm{Q} 1$ = First quartile of total DDD used by conventional $(\mathrm{CON})$ farms.

${ }^{2}$ Extra-label use.

${ }^{3}$ Includes amoxicillin.

farm were included in the analysis to avoid statistical dependence.

\section{RESULTS}

\section{Antimicrobial Usage in Conventional Herds}

A complete description of antimicrobial usage on study farms has been published separately (Pol and Ruegg, 2007). $\beta$-Lactams, including cephapirin, penicillin, and ceftiofur, were used on the majority of the farms (Table 1). Pirlimycin and tetracycline were used on more than $75 \%$ of the farms and cephapirin, penicillin, and ceftiofur were used in all herds surveyed (Table 1). All cephapirin was administered by intramammary infusion. The majority (75\%) of DDD of cephapirin per cow per year were attributable to treatment of clinical mastitis, and DCT accounted for the rest (25\%). Penicillin was used for intramammary (54\% of total number of DDD used) and parenteral treatments (46\%). Dry cow therapy accounted for almost all the intramammary usage of penicillin. Penicillin was given parenterally on 15 farms. Almost half (49\%) of the DDD of penicillin used parenterally were attributed to treatment of clinical mastitis, whereas parenteral treatment at dry-off (22\%), treatment of foot infections (14\%), treatment of metritis (10\%), and treatment of respiratory infections (4\%) accounted for the remainder.

Three farms reported extralabel use of ceftiofur for intramammary treatments, but only 1 provided suffi- cient data for calculation of density of usage. The intramammary usage of ceftiofur in this farm accounted for $60 \%$ of the total usage on all farms. Parenteral treatments using ceftiofur were reported by all farms. More than one-third (37\%) of parenteral ceftiofur was for treatment of foot infections. Ceftiofur was administered parenterally for treatment of metritis (28\%), clinical mastitis (24\%), and respiratory infections (11\%). All tetracycline was administered parenterally and usage at dry-off represented $37 \%$ of total usage. Tetracycline was used for treatment of clinical mastitis (21\%), metritis (18\%), foot infections (13\%), and respiratory infections $(10 \%)$. All reported usage of pirlimycin was for intramammary treatments of clinical mastitis.

\section{Mastitis Pathogens}

A total of 3,338 and 2,334 quarter milk samples were obtained from CON ( $\mathrm{n}=854$ cows) and ORG ( $\mathrm{n}=599$ cows) farms, respectively. More samples (58.4\%) obtained from CON farms yielded no growth compared with samples obtained from ORG farms (44.4\%; Table 2 ). The prevalence of all mastitis pathogens, except coliforms, was greater for ORG farms compared with CON farms (Table 2).

Of the total mastitis pathogens isolated ( $\mathrm{n}=1,197$ for CON vs. $\mathrm{n}=1,306$ for ORG), significant differences $(P<0.01)$ in the proportion of pathogens based on farm type were observed for CNS (38\% CON and 30\% ORG), 
Table 2. Microbiological results obtained from quarter milk samples from cows on conventional ( $\mathrm{n}=3,338$ quarters; $\mathrm{n}=20$ farms) and organic ( $\mathrm{n}=2,334$; quarters, $\mathrm{n}=20$ farms) dairy herds

\begin{tabular}{|c|c|c|c|c|c|}
\hline \multirow[b]{2}{*}{ Isolate } & \multicolumn{2}{|c|}{ Conventional } & \multicolumn{2}{|c|}{ Organic } & \multirow[b]{2}{*}{$P$} \\
\hline & $\mathrm{n}$ & $\%$ & $\mathrm{n}$ & $\%$ & \\
\hline No growth & 1,950 & 58.4 & 1,038 & 44.4 & $<0.001$ \\
\hline CNS & 455 & 13.6 & 395 & 16.9 & 0.001 \\
\hline Streptococcus spp. & 213 & 6.3 & 192 & 8.2 & 0.011 \\
\hline Staphylococcus aureus & 98 & 2.9 & 128 & 5.4 & $<0.001$ \\
\hline Coliforms & 66 & 1.9 & 12 & 0.5 & $<0.001$ \\
\hline Streptococcus agalactiae & 30 & 0.8 & 55 & 2.3 & $<0.001$ \\
\hline Other $^{1}$ & 335 & 10.0 & 524 & 22.4 & $<0.001$ \\
\hline Contaminated & 338 & 10.1 & 107 & 4.4 & $<0.001$ \\
\hline
\end{tabular}

${ }^{1}$ Includes Corynebacterium spp. and Bacillus spp.

Strep. agalactiae (2\% CON and 4\% ORG), Strep. spp. (18\% CON and $15 \%$ ORG), coliforms (6\% CON and $<1 \%$ ORG), and other pathogens (27\% CON and 40\% ORG). No significant differences were found in the proportion of Staph. aureus isolated based on herd type (8.5\% of isolates).

\section{Antimicrobial Susceptibility}

The number of Staph. aureus isolates per farm used in statistical analysis ranged from 1 to 9 in CON herds, whereas in ORG herds it ranged from 1 to 18 due to the limitation of only 1 isolate per cow and $\geq 20$ per farm. A total of 52 and 85 Staph. aureus obtained from CON $(\mathrm{n}=15)$ and ORG $(\mathrm{n}=18)$ farms, respectively, were used for statistical analysis. The number of CNS isolates per farm used in statistical analysis ranged from 2 to 16 in CON herds, whereas in ORG herds it ranged from 1 to 16 . A total of 160 and $135 \mathrm{CNS}$ obtained from CON $(n=20)$ and ORG $(n=19)$ farms, respectively, were used for statistical analysis. The number of Strep. spp. isolates per farm used in statistical analysis ranged from 1 to 5 in CON herds, whereas in ORG herds it ranged from 1 to 7 . A total of 42 and 53 Strep. spp. obtained from CON $(\mathrm{n}=17)$ and ORG ( $\mathrm{n}=19)$ farms, respectively, were used for statistical analysis.

Almost all Staph. aureus obtained from both types of farm were inhibited by the lowest concentrations of ampicillin, cephalothin, oxacillin, penicillin, penicillin/ novobiocin, and tetracycline (Table 3). Almost all the Staph. aureus obtained from ORG farms, but only $75 \%$ of Staph. aureus obtained from CON farms, were inhibited by the lowest concentration of pirlimycin. About $75 \%$ of the isolates obtained from both farm types were inhibited by the lowest concentration of erythromycin. About $50 \%$ of the isolates obtained from both farm types were inhibited by the lowest concentration of ceftiofur. A minority of the isolates obtained from CON (5.8\%) and ORG (17.6\%) were inhibited at the lowest concentration of sulfadimethoxine (Table 3). Farm type was associated with the MIC of pirlimycin for Staph. aureus $\left(\chi^{2}=9.4 ; P=0.009\right)$, and with the MIC of sulfadimethoxine for Staph. aureus $\left(\chi^{2}=8.6 ; P=0.033\right)$. Farm type was not associated with the MIC of the other antimicrobial drugs tested with Staph. aureus $(P>0.18)$. Staph. aureus isolates obtained from CON herds were more likely to be resistant to ampicillin (odds ratio $=7.7 ; P=$ 0.003 ) and penicillin (odds ratio $=6.3 ; P=0.01$ ) compared with isolates obtained from ORG herds.

Almost all isolates of CNS obtained from both farm types were inhibited by the lowest concentration of ampicillin, ceftiofur, cephalothin, erythromycin, oxacillin, penicillin, penicillin/novobiocin, and tetracycline (Table 4). Most of the CNS isolates obtained from ORG farms were inhibited at the lowest concentration of pirlimycin, whereas only $67 \%$ of the isolates obtained from CON farms were inhibited at that concentration. Almost half of the isolates obtained from both farm types were inhibited at the lowest concentration of sulfadimethoxine (Table 4). Farm type was associated with the MIC of ampicillin $\left(\chi^{2}=12.1 ; P=0.029\right)$, MIC of pirlimycin $\left(\chi^{2}=\right.$ $42.7 ; P<0.001)$, and MIC of tetracycline $\left(\chi^{2}=12.9 ; P=\right.$ 0.001 ). Farm type was not associated with the MIC of the other antimicrobial drugs tested using CNS $(P>$ 0.09). Coagulase-negative staphylococci isolates obtained from $\mathrm{CON}$ herds were more likely to be resistant to ampicillin (odds ratio $=2.4 ; P=0.009$ ), penicillin (odds ratio $=2.2 ; P=0.01$ ), pirlimycin (odds ratio $=$ 29.4; $P<0.0001$ ), and tetracycline (odds ratio $=9.4 ; P=$ $0.0004)$ than those from ORG.

Almost all the isolates of Strep. spp. obtained from both farm types were inhibited by the lowest concentrations of ampicillin, ceftiofur, cephalothin, erythromycin, oxacillin, penicillin, and penicillin/novobiocin (Table 5). Almost all the Strep. spp. obtained from ORG farms, but only $64 \%$ of the isolates obtained from CON farms, were inhibited by the lowest concentration of pirlimycin. About half of the isolates obtained from both farm types were inhibited by the lowest concentration of sulfadimethoxine. The majority of the Strep. spp. obtained from ORG farms were inhibited at the lowest concentration of tetracycline, whereas only $51 \%$ of the isolates obtained from $\mathrm{CON}$ farms were inhibited at this concentration (Table 5). Farm type was associated with the MIC of pirlimycin $\left(\chi^{2}=16.17 ; P<0.001\right)$, and with the MIC of tetracycline $\left(\chi^{2}=157 ; P=0.001\right)$. Farm type was not associated with the MIC of the other antimicrobial drugs tested with Strep. spp. $(P>0.19)$. Streptococcus spp. isolates obtained from CON herds were more likely to be resistant to pirlimycin (odds ratio $=14.1 ; P=0.002$ ) and tetracycline (odds ratio $=$ $6.1 ; P=0.0003)$. 
Table 3. Minimum inhibitory concentration of selected Staphylococcus aureus isolates obtained from conventional $(\mathrm{CON}, \mathrm{n}=15)$ and organic $(\mathrm{ORG}, \mathrm{n}=18)$ farms $^{1}$

\begin{tabular}{|c|c|c|c|c|c|c|c|c|c|c|c|c|c|c|c|}
\hline \multirow[b]{2}{*}{ Drug } & \multirow{2}{*}{$\begin{array}{l}\text { Farm } \\
\text { type }\end{array}$} & \multirow[b]{2}{*}{$\mathrm{n}$} & \multicolumn{13}{|c|}{ Percentage of isolates at each indicated MIC $(\mu \mathrm{g} / \mathrm{mL})^{2}$} \\
\hline & & & 0.12 & 0.25 & 0.5 & 1 & 2 & 4 & 8 & 16 & 32 & 64 & 128 & 256 & $\mathrm{NI}^{3}$ \\
\hline Ampicillin ${ }^{4}$ & $\mathrm{CON}$ & 46 & 93.5 & & $6.5^{*}$ & $*$ & $*$ & $*$ & $*$ & - & - & - & - & - & - \\
\hline \multirow[t]{2}{*}{ Ceftiofur ${ }^{5}$} & $\mathrm{CON}$ & 51 & -7 & - & 56.9 & 33.3 & 9.8 & $*$ & - & - & - & - & - & - & - \\
\hline & ORG & 85 & - & - & 55.3 & $\overline{38.9}$ & 5.8 & $*$ & - & - & - & - & - & - & - \\
\hline \multirow[t]{2}{*}{ Cephalothin ${ }^{4}$} & $\mathrm{CON}$ & 51 & - & - & - & - & 100.0 & & & $*$ & - & - & - & - & - \\
\hline & ORG & 85 & - & - & - & - & 98.8 & 1.2 & & $*$ & - & - & - & - & - \\
\hline \multirow[t]{2}{*}{ Oxacillin ${ }^{4}$} & $\mathrm{CON}$ & 52 & - & - & 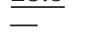 & - & 98.1 & $1.9 *$ & - & - & - & - & - & - & - \\
\hline & ORG & 85 & - & - & - & - & 100.0 & $*$ & - & - & - & - & - & - & - \\
\hline \multirow[t]{2}{*}{ Penicillin $^{4}$} & CON & 84 & 88.2 & $5.9^{*}$ & $3.9 *$ & $2.0^{*}$ & $*$ & $*$ & $*$ & - & - & - & - & - & - \\
\hline & ORG & 51 & 97.6 & $2.4^{*}$ & $*$ & $*$ & $*$ & $*$ & $*$ & - & - & - & - & - & - \\
\hline \multirow{2}{*}{ Penicillin/novobiocin ${ }^{6}$} & $\mathrm{CON}$ & 52 & - & - & - & 100.0 & * & * & $*$ & - & - & - & - & - & - \\
\hline & ORG & 85 & - & - & - & 100.0 & $*$ & $*$ & $*$ & - & - & - & - & - & - \\
\hline Pirlimycin $^{6}$ & $\mathrm{CON}$ & 52 & - & - & 76.9 & $\underline{13.5}$ & 9.6 & $*$ & - & - & - & - & - & - & - \\
\hline Tetracycline $^{4}$ & ORG & 85 & - & - & - & 96.4 & 1.2 & 1.2 & $1.2^{*}$ & - & - & - & - & - & - \\
\hline
\end{tabular}

\footnotetext{
${ }^{1} \mathrm{~A}$ maximum of 1 isolate per cow and 20 isolates per farm were included.

${ }^{2}$ The MIC values that inhibits half of the isolates $\left(\mathrm{MIC}_{50}\right)$ are shown in italic font. The MIC value that inhibits $90 \%$ of the isolates $\left(\mathrm{MIC}_{90}\right)$ is underlined. A value shown in bold font is both the $\mathrm{MIC}_{50}$ and $\mathrm{MIC}_{90}$. Cells with an asterisk indicate tested antimicrobial concentrations above breakpoint (MIC at which an isolate is considered susceptible according to Clinical and Laboratory Standards Institute guidelines).

${ }^{3} \mathrm{NI}=$ Not inhibited (growth at highest concentration tested).

${ }^{4}$ Interpretive criteria based on human data.

${ }^{5}$ Interpretive criteria based on bovine respiratory disease.

${ }^{6}$ Interpretive criteria based on bovine mastitis.

${ }^{7}$ Dash indicates values not tested for the indicated antimicrobial drug; empty cells represent tested antimicrobial concentrations without inhibited isolates.
}

Homogeneous survival curves were observed for all isolates studied for the usage groups (ORG, CON-L, CON-H) of ceftiofur, cephapirin, oxacillin, penicillin/ novobiocin, and sulfadimethoxine (Log-Rank > 0.10; Wilcoxon > 0.11). Homogeneity was observed in the Staph. aureus survival curves for ampicillin, erythromycin, and tetracycline based on usage groups (Log Rank > 0.20; Wilcoxon >0.11). Survival curves of Staph. aureus showed heterogeneity among usage groups (ORG, CON-L, CON-H) of penicillin (Table 6 and Figure 1) and pirlimycin (Table 6). The median survival concentration to inhibit Staph. aureus was the lowest concentration tested of penicillin and pirlimycin for all usage groups. The MIC that inhibited $90 \%$ ( $\mathbf{M I C}_{\mathbf{9 0}}$ ) of the Staph. aureus obtained from ORG herds for penicillin and pirlimycin was lower than the $\mathrm{MIC}_{90}$ of the isolates obtained from CON-L and CON-H farms (Table 6, Figure 1). No Staph. aureus isolate was censored for penicillin or pirlimycin.

Survival curves of CNS demonstrated heterogeneity among usage groups (ORG, CON-L, CON-H) of ampicillin, erythromycin, penicillin, pirlimycin, and tetracycline (Table 6, Figures 2 and 3 ). The lowest concentra- tions tested of ampicillin, penicillin, and tetracycline inhibited at least half of all isolates for all usage groups. Most CNS obtained from ORG and CON-L herds were inhibited by the lowest concentration tested for erythromycin $(0.25 \mu \mathrm{g} / \mathrm{mL})$, whereas the MIC that inhibited $50 \%\left(\mathbf{M I C}_{50}\right)$ for isolates obtained from $\mathrm{CON}-\mathrm{H}$ herds was $0.5 \mu \mathrm{g} / \mathrm{mL}$. The $\mathrm{MIC}_{90}$ of the CNS obtained from ORG herds for ampicillin, penicillin, pirlimycin, and tetracycline was lower than the $\mathrm{MIC}_{90}$ of the isolates obtained from CON-L and CON-H farms (Table 6, Figures 2 and 3). The $\mathrm{MIC}_{90}$ of the CNS obtained from CON-L and CON-H farms for pirlimycin $(4 \mu \mathrm{g} / \mathrm{mL})$ and tetracycline $(8 \mu \mathrm{g} / \mathrm{mL})$ was the highest concentration tested (Table 6). No differences were observed in the $\mathrm{MIC}_{90}$ for erythromycin $(0.5 \mu \mathrm{g} / \mathrm{mL})$ for any usage groups (Table 6). Censoring for pirlimycin occurred in $1 \mathrm{CNS}$ isolate obtained from CON-L farms and in 14 isolates obtained from CON-H farms. Censoring for tetracycline occurred in 2 isolates obtained from ORG, in 7 isolates obtained from CON-L, and in 10 isolates obtained from CON-H herds (Table 6).

Survival curves of Strep. spp. showed heterogeneity among usage groups (ORG, CON-L, CON-H) of pirli- 
Table 4. Minimum inhibitory concentration of selected CNS isolates obtained from conventional $(C O N, n=20)$ and organic $($ ORG, $n=19)$ farms $^{1}$

\begin{tabular}{|c|c|c|c|c|c|c|c|c|c|c|c|c|c|c|c|}
\hline \multirow[b]{2}{*}{ Drug } & \multirow{2}{*}{$\begin{array}{l}\text { Farm } \\
\text { type }\end{array}$} & \multirow[b]{2}{*}{$\mathrm{n}$} & \multicolumn{13}{|c|}{ Percentage of isolates at each indicated MIC $(\mu \mathrm{g} / \mathrm{mL})^{2}$} \\
\hline & & & 0.12 & 0.25 & 0.5 & 1 & 2 & 4 & 8 & 16 & 32 & 64 & 128 & 256 & $\mathrm{NI}^{3}$ \\
\hline Ampicillin ${ }^{4}$ & $\mathrm{CON}$ & 141 & 87.2 & $\underline{2.8}$ & $5.0^{*}$ & $2.8^{*}$ & $1.4^{*}$ & $*$ & * & - & - & - & - & - & 0.7 \\
\hline \multirow[t]{2}{*}{ Ceftiofur $^{5}$} & $\mathrm{CON}$ & 156 & -7 & - & 83.3 & $\underline{12.2}$ & 3.8 & $0.7^{*}$ & - & - & - & - & - & - & - \\
\hline & ORG & 134 & - & - & 88.0 & $\overline{7.5}$ & 4.5 & $*$ & - & - & - & - & - & - & - \\
\hline \multirow[t]{2}{*}{ Cephalothin ${ }^{4}$} & $\mathrm{CON}$ & 156 & - & - & - & - & 99.4 & 0.6 & & $*$ & - & - & - & - & - \\
\hline & ORG & 135 & - & - & - & - & 97.0 & 1.5 & 0.7 & $0.7^{*}$ & - & - & - & - & - \\
\hline \multirow[t]{2}{*}{ Oxacillin $^{4}$} & $\mathrm{CON}$ & 160 & - & - & $\overline{-}$ & - & 98.7 & $1.3^{*}$ & - & - & - & - & - & - & - \\
\hline & ORG & 135 & - & - & - & - & 100.0 & $*$ & - & - & - & - & - & - & - \\
\hline \multirow[t]{2}{*}{ Penicillin ${ }^{4}$} & $\mathrm{CON}$ & 158 & 80.4 & $\underline{8.9 *}$ & $4.4^{*}$ & $0.6^{*}$ & $1.9^{*}$ & $0.6^{*}$ & $1.8^{*}$ & - & - & - & - & - & 1.2 \\
\hline & ORG & 134 & 90.3 & $\overline{8.2} *$ & $0.7^{*}$ & $0.7 *$ & $*$ & $*$ & $*$ & - & - & - & - & - & - \\
\hline \multirow[t]{2}{*}{ Penicillin/novobiocin ${ }^{6}$} & $\mathrm{CON}$ & 159 & - & - & - & 98.7 & $0.6^{*}$ & $0.6^{*}$ & $*$ & - & - & - & - & - & - \\
\hline & ORG & 135 & - & - & - & 100.0 & $*$ & $*$ & $*$ & - & - & - & - & - & - \\
\hline Pirlimycin $^{6}$ & $\mathrm{CON}$ & 160 & - & - & 66.9 & 6.2 & 8.7 & $8^{8.7^{*}}$ & - & - & - & - & - & - & 9.3 \\
\hline Tetracycline $^{4}$ & ORG & 134 & - & - & - & 93 & 3.0 & 2.2 & $*$ & - & - & - & - & - & $\overline{1.5}$ \\
\hline
\end{tabular}

${ }^{1} \mathrm{~A}$ maximum of 1 isolate per cow and 20 isolates per farm were included.

${ }^{2}$ The MIC values that inhibits half of the isolates $\left(\mathrm{MIC}_{50}\right)$ are shown in italic font. The MIC value that inhibits $90 \%$ of the isolates $\left(\mathrm{MIC}_{90}\right)$ is underlined. A value shown in bold font is both the $\mathrm{MIC}_{50}$ and $\mathrm{MIC}_{90}$. Cells with an asterisk indicate tested antimicrobial concentrations above breakpoint (MIC at which an isolate is considered susceptible according to Clinical and Laboratory Standards Institute guidelines).

${ }^{3} \mathrm{NI}=$ Not inhibited (growth at highest concentration tested).

${ }^{4}$ Interpretive criteria based on human data.

${ }^{5}$ Interpretive criteria based on bovine respiratory disease.

${ }^{6}$ Interpretive criteria based on bovine mastitis.

${ }^{7}$ Dash indicates values not tested for the indicated antimicrobial drug; empty cells represent tested antimicrobial concentrations without inhibited isolates.

mycin and tetracycline (Table 6). Homogeneous survival curves were observed among usage groups of ampicillin, erythromycin, and penicillin (Log-Rank $=0.10$; Wilcoxon = 0.11). The $\mathrm{MIC}_{50}$ for pirlimycin was at least the lowest concentration tested for all usage groups. The $\mathrm{MIC}_{50}$ for tetracycline was at least the lowest concentration tested $(1 \mu \mathrm{g} / \mathrm{mL})$ for Strep. spp. obtained from ORG and CON-L, whereas the $\mathrm{MIC}_{50}$ for isolates obtained from CON-H herds was at least $2 \mu \mathrm{g} / \mathrm{mL}$. The $\mathrm{MIC}_{90}$ of the Strep. spp. obtained from ORG farms was the lowest concentration $(0.5 \mu \mathrm{g} / \mathrm{mL})$ for pirlimycin, but was the highest concentration $(4 \mu \mathrm{g} / \mathrm{mL})$ for isolates obtained from CON-L and CON-H farms. The $\mathrm{MIC}_{90}$ of the Strep. spp. for tetracycline was the highest concentration tested $(8 \mu \mathrm{g} / \mathrm{mL})$ for all usage groups (Table 6). Censoring for pirlimycin occurred in 3 isolates obtained from CON-L and in 2 isolates obtained from CON-H herds. Censoring for tetracycline occurred in 6 isolates obtained from ORG, in 5 isolates obtained from CON-L, and in 9 isolates obtained from $\mathrm{CON}-\mathrm{H}$ herds (Table 6).

\section{DISCUSSION}

Enrollment criteria were designed to select farms with varying levels of exposure to antimicrobial drugs and appeared to be successful. The farms enrolled in this study presented different levels of exposure to antimicrobial drugs as demonstrated by differences in DDD among farms and the variety of antimicrobial drugs used in CON dairy farms to treat clinically or subclinically diseased animals and the minimal exposure to antimicrobial drugs in ORG farms.

Farm-level exposure to antimicrobial drugs was calculated based on farmers' recall. Zwald et al. (2004) used a similar approach. The risk of introducing recall and reporting biases exists with collection of all types of farm data. Sawant et al. (2005) reported that only $30 \%$ of the farms surveyed in Pennsylvania had records on herd health and antimicrobial drug usage, whereas only $15 \%$ of each of the groups of the present study maintained some type of computerized records (data not shown). In a recent survey of Wisconsin farmers, Hoe and Ruegg (2006) reported that $19 \%$ of the responders from very small herds ( $<50$ cows), $18 \%$ of the small herds (50 to 100 cows), and $15 \%$ of the medium herds (100 to 200) did not keep any records of antimicrobial drug treatments. Therefore, the estimation of antimicrobial usage using farmers' recall (aided by photos of veterinary antimicrobial products) using an extensive 
Table 5. Minimum inhibitory concentration of selected Streptococcus spp. (except Strep. agalactiae) isolates obtained from conventional $(\mathrm{CON}, \mathrm{n}=17)$ and organic $(\mathrm{ORG}, \mathrm{n}=19)$ farms $^{1}$

\begin{tabular}{|c|c|c|c|c|c|c|c|c|c|c|c|c|c|c|c|}
\hline \multirow[b]{2}{*}{ Drug } & \multirow{2}{*}{$\begin{array}{l}\text { Farm } \\
\text { type }\end{array}$} & \multirow[b]{2}{*}{$\mathrm{n}$} & \multicolumn{13}{|c|}{ Percentage of isolates at each indicated MIC $(\mu \mathrm{g} / \mathrm{mL})^{2}$} \\
\hline & & & 0.12 & 0.25 & 0.5 & 1 & 2 & 4 & 8 & 16 & 32 & 64 & 128 & 256 & $\mathrm{NI}^{3}$ \\
\hline Ampicillin $^{4}$ & $\mathrm{CON}$ & 42 & 92.9 & 4.8 & $*$ & $*$ & $2.4^{*}$ & $*$ & $*$ & - & - & - & - & - & - \\
\hline \multirow{2}{*}{ Ceftiofur ${ }^{5}$} & $\mathrm{CON}$ & 42 & -7 & - & 95.2 & 2.4 & & $*$ & - & - & - & - & - & - & 2.4 \\
\hline & ORG & 53 & - & - & 98.1 & 1.9 & & $*$ & - & - & - & - & - & - & - \\
\hline \multirow{2}{*}{ Cephalothin $^{4}$} & $\mathrm{CON}$ & 42 & - & - & - & - & 95.2 & 2.4 & & $*$ & - & - & - & - & 2.4 \\
\hline & ORG & 53 & - & - & - & - & 100.0 & & & $*$ & - & - & - & - & - \\
\hline \multirow[t]{2}{*}{ Oxacillin ${ }^{4}$} & $\mathrm{CON}$ & 42 & - & - & - & - & 95.2 & $2.4^{*}$ & - & - & - & - & - & - & 2.4 \\
\hline & ORG & 53 & - & - & - & - & 100.0 & $*$ & - & - & - & - & - & - & - \\
\hline \multirow{2}{*}{ Penicillin $^{4}$} & $\mathrm{CON}$ & 42 & 90.5 & $7.2^{*}$ & $*$ & $*$ & $2.4^{*}$ & $*$ & $*$ & - & - & - & - & - & - \\
\hline & ORG & 53 & 90.6 & $9.4^{*}$ & $*$ & $*$ & $*$ & $*$ & * & - & - & - & - & - & - \\
\hline \multirow[t]{2}{*}{ Penicillin/novobiocin ${ }^{6}$} & $\mathrm{CON}$ & 42 & - & - & - & 100.0 & $*$ & $*$ & $*$ & - & - & - & - & - & - \\
\hline & ORG & 53 & - & - & - & 100.0 & $*$ & $*$ & $*$ & - & - & - & - & - & - \\
\hline Pirlimycin ${ }^{6}$ & $\mathrm{CON}$ & 42 & - & - & 64.3 & 4.8 & 7.1 & $11.9^{*}$ & - & - & - & - & - & - & $\underline{11.9}$ \\
\hline Tetracycline $^{4}$ & ORG & 53 & - & - & - & 83.0 & 5.7 & $*$ & $*$ & - & - & - & - & - & $\overline{\overline{11.3}}$ \\
\hline
\end{tabular}

\footnotetext{
${ }^{1} \mathrm{~A}$ maximum of 1 isolate per cow and 20 isolates per farm were included.

${ }^{2}$ The MIC values that inhibits half of the isolates $\left(\mathrm{MIC}_{50}\right)$ are shown in italic font. The MIC value that inhibits $90 \%$ of the isolates $\left(\mathrm{MIC}_{90}\right)$ is underlined. A value shown in bold font is both the $\mathrm{MIC}_{50}$ and $\mathrm{MIC}_{90}$. Cells with an asterisk indicate tested antimicrobial concentrations above breakpoint (MIC at which an isolate is considered susceptible according to Clinical and Laboratory Standards Institute guidelines).

${ }^{3} \mathrm{NI}=$ Not inhibited (growth at highest concentration tested).

${ }^{4}$ Interpretive criteria based on human data.

${ }^{5}$ Interpretive criteria based on bovine respiratory disease.

${ }^{6}$ Interpretive criteria based on bovine mastitis.

${ }^{7}$ Dash indicates values not tested for the indicated antimicrobial drug; empty cells represent tested antimicrobial concentrations without inhibited isolates.
}

questionnaire with specific questions about treatment practices may be a good estimator of the antimicrobial drug usage in the studied farms.

The goal of this study was to analyze relationships between antimicrobial usage at the farm level and antimicrobial susceptibility of mastitis pathogens. Exclusive enrollment of multiparous cows ensured exposure to at least 1 known antimicrobial drug (DCT). The DDD estimates demonstrated that most cows had additional antimicrobial exposures. It is also possible that some cows received medicated milk replacer as calves. Our study estimated exposure to DCT during the previous $5 \mathrm{yr}$ and exposure to other antimicrobial drugs used for treatments during the previous $2 \mathrm{yr}$. The differential periods of recall were based on the assumption that DCT was more easily recalled than other treatments and were used to avoid problems with recall bias. Susceptibility of mastitis pathogens obtained from cows enrolled from CON herds was compared with susceptibility results of mastitis pathogens obtained from multiparous cows from ORG herds that received minimal or no exposure to antimicrobial drugs. The mean time since ORG farms were certified organic was $7.6 \mathrm{yr}$. Only
1 ORG producer reported the use of DCT in a few quarters. No other uses of antimicrobial drugs were reported by ORG farmers. Therefore, antimicrobial exposure in ORG dairy farms may be considered minimal.

More IMI were present in ORG herds compared with CON herds. Milk samples obtained from ORG herds yielded significantly more bacteria compared with samples originating from CON herds. All isolates, except coliforms, were more prevalent in ORG herds compared with CON herds (Table 2). Intramammary pathogens that can be easily controlled using antimicrobial therapy (i.e., Strep. agalactiae) were more prevalent in ORG herds. The prevalence of Strep. agalactiae was almost 3 times higher in ORG than in CON herds. Prevention of Strep. agalactiae infections should be a priority on organic farms.

Antimicrobial susceptibility data may be categorized as susceptible-intermediate-resistant (SIR) or may be expressed as the MIC. The MIC is the lowest concentration of antimicrobial agent that completely inhibits bacterial growth (Prescott et al., 2000; Clinical and Laboratory Standards Institute, 2002). The susceptible-intermediate-resistant categories are based on MIC 
Table 6. Life table and survivor function analysis of selected pathogens for selected antimicrobial drugs stratified by antimicrobial drug usage category

\begin{tabular}{|c|c|c|c|c|c|c|c|c|}
\hline Isolate and drug & Usage $^{1}$ & $\mathrm{n}^{2}$ & $\mathrm{DDD}^{3}$ & $\mathrm{MIC}_{50}{ }^{4}$ & $\mathrm{MIC}_{90}{ }^{5}$ & Censor $^{6}$ & Log-Rank ${ }^{7}$ & Wilcox ${ }^{8}$ \\
\hline \multicolumn{9}{|l|}{ Staph. aureus } \\
\hline \multirow[t]{3}{*}{ Penicillin } & ORG & 84 & 0.00 & 0.12 & 0.12 & 0 & \multirow[t]{3}{*}{0.039} & \multirow[t]{3}{*}{0.077} \\
\hline & CON-L & 17 & 0.26 & 0.12 & 0.25 & 0 & & \\
\hline & CON-H & 34 & 1.32 & 0.12 & 0.25 & 0 & & \\
\hline \multirow[t]{3}{*}{ Pirlimycin } & ORG & 85 & 0.00 & 0.50 & 0.50 & 0 & \multirow[t]{3}{*}{0.006} & \multirow[t]{3}{*}{0.004} \\
\hline & CON-L & 15 & 0.05 & 0.50 & 1.00 & 0 & & \\
\hline & CON-H & 37 & 0.94 & 0.50 & 2.00 & 0 & & \\
\hline \multicolumn{9}{|l|}{ CNS } \\
\hline \multirow[t]{3}{*}{ Ampicillin } & ORG & 126 & 0.00 & 0.12 & 0.12 & 0 & \multirow[t]{3}{*}{0.006} & \multirow[t]{3}{*}{0.126} \\
\hline & CON-L & 80 & $<0.01$ & 0.12 & 0.25 & 0 & & \\
\hline & CON-H & 60 & 0.58 & 0.12 & 0.50 & 1 & & \\
\hline \multirow[t]{3}{*}{ Erythromycin } & ORG & 133 & 0.00 & 0.25 & 0.50 & 4 & \multirow[t]{3}{*}{0.460} & \multirow[t]{3}{*}{0.038} \\
\hline & CON-L & 154 & $<0.01$ & 0.25 & 0.50 & 6 & & \\
\hline & CON-H & 5 & 0.15 & 0.50 & 0.50 & 0 & & \\
\hline \multirow[t]{3}{*}{ Penicillin } & ORG & 134 & 0.00 & 0.12 & 0.12 & 0 & \multirow[t]{3}{*}{0.004} & \multirow[t]{3}{*}{0.007} \\
\hline & CON-L & 43 & 0.26 & 0.12 & 0.25 & 0 & & \\
\hline & CON-H & 115 & 1.32 & 0.12 & 0.50 & 2 & & \\
\hline \multirow[t]{3}{*}{ Pirlimycin } & ORG & 134 & 0.00 & 0.50 & 0.50 & 0 & \multirow[t]{3}{*}{$<0.001$} & \multirow[t]{3}{*}{$<0.001$} \\
\hline & CON-L & 72 & 0.05 & 0.50 & 4.00 & 1 & & \\
\hline & CON-H & 88 & 0.94 & 0.50 & 4.00 & 14 & & \\
\hline \multirow[t]{3}{*}{ Tetracycline } & ORG & 134 & 0.00 & 1.00 & 1.00 & 2 & \multirow[t]{3}{*}{0.001} & \multirow[t]{3}{*}{0.004} \\
\hline & CON-L & 70 & 0.01 & 1.00 & 8.00 & 7 & & \\
\hline \multirow{2}{*}{\multicolumn{9}{|c|}{ Strep. spp. }} \\
\hline & & & & & & & & \\
\hline \multirow[t]{3}{*}{ Pirlimycin } & ORG & 53 & 0.00 & 0.50 & 0.50 & 0 & \multirow[t]{3}{*}{$<0.001$} & \multirow[t]{3}{*}{$<0.001$} \\
\hline & CON-L & 16 & 0.05 & 0.50 & 4.00 & 3 & & \\
\hline & CON-H & 26 & 0.94 & 0.50 & 4.00 & 2 & & \\
\hline \multirow[t]{3}{*}{ Tetracycline } & ORG & 53 & 0.00 & 1.00 & 8.00 & 6 & \multirow[t]{3}{*}{0.006} & 0.001 \\
\hline & CON-L & 19 & 0.01 & 1.00 & 8.00 & 5 & & \\
\hline & CON-H & 22 & 0.32 & 2.00 & 8.00 & 9 & & \\
\hline
\end{tabular}

${ }^{1} \mathrm{ORG}=$ Organic farms (no use of antimicrobial drugs); CON-L = conventional farms, low usage (no use of the studied antimicrobial drug or use less or equal than the studied farm's first quartile); CON-H = conventional farms, high usage (use more than the studied farm's first quartile).

${ }^{2}$ Number of isolates.

${ }^{3}$ Average number of defined daily doses (DDD) used in farms at each indicated usage category.

${ }^{4}$ The MIC value that inhibits $50 \%$ of the isolates.

${ }^{5}$ The MIC value that inhibits $90 \%$ of the isolates.

${ }^{6}$ Number of isolates censored (observed growth at the highest antimicrobial drug concentration of the used test).

${ }^{7}$ Log-Rank test for equality of strata at higher antimicrobial concentrations.

${ }^{8}$ Wilcoxon test for equality of strata at lower antimicrobial concentrations.

breakpoints defined by CLSI (Clinical and Laboratory Standards Institute, 2002). The MIC provides more continuous data (ordinal data) that might reflect better the differences among groups. For example, in this study, all the MIC of the Staph. aureus isolates were below the breakpoint for pirlimycin. But herd type was associated with the MIC for pirlimycin and the survival curves of Staph. aureus isolates were heterogeneous for pirlimycin usage groups. Therefore, MIC, rather than proportion of susceptible, was more useful for monitoring subtle changes relative to antimicrobial drug exposure.

Comparison of antimicrobial resistance of mastitis pathogens among studies is difficult because of differences in methodology (Erskine et al., 2004). Minimum inhibitory concentrations of pathogens isolated in this study were generally low and comparable to MIC values reported previously for Staph. aureus (DeOliveira et al., 2000), CNS (Rajala-Schultz et al., 2004), and Strep. spp. (Rossitto et al., 2002). The majority of the isolates $(>80 \%)$ obtained from both farm types were inhibited at the lowest concentration of all $\beta$-lactams that are commonly used for treatment of mastitis. The only exception was the combination of ceftiofur and Staph. aureus, where the lowest concentration only inhibited about half of the isolates obtained from both farm types. This trend has been previously reported (DeOliveira et al., 2000). The proportion of resistant isolates was generally small and for most antimicrobial drugs, fewer resistant isolates were obtained from ORG farms. Nevertheless, a high proportion of isolates resistant to sulfadimethoxine were observed in both farm types. The proportion of Strep. spp. isolates that were resistant to 


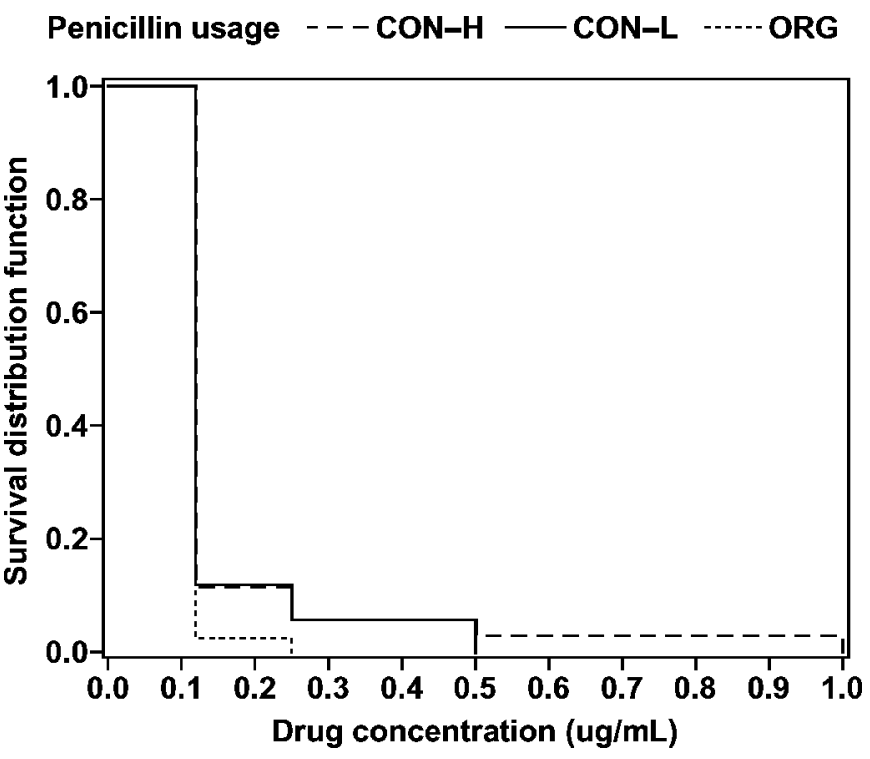

Figure 1. Kaplan-Meier plot showing survival proportion of 135 Staphylococcus aureus isolates stratified on organic farms $(\mathrm{ORG} ; \mathrm{n}=$ 84), no use of penicillin or use less than or equal to the first quartile of usage (CON-L; $\mathrm{n}=17$ ) or penicillin use greater than the first quartile of usage $(\mathrm{CON}-\mathrm{H} ; \mathrm{n}=34)$. Log-Rank test for equality of strata at higher minimum inhibitory concentration (MIC), $\chi^{2}=6.45$, $P=0.039$. Wilcoxon test for equality of strata at lower MIC, $\chi^{2}=$ $5.12, P=0.077$.

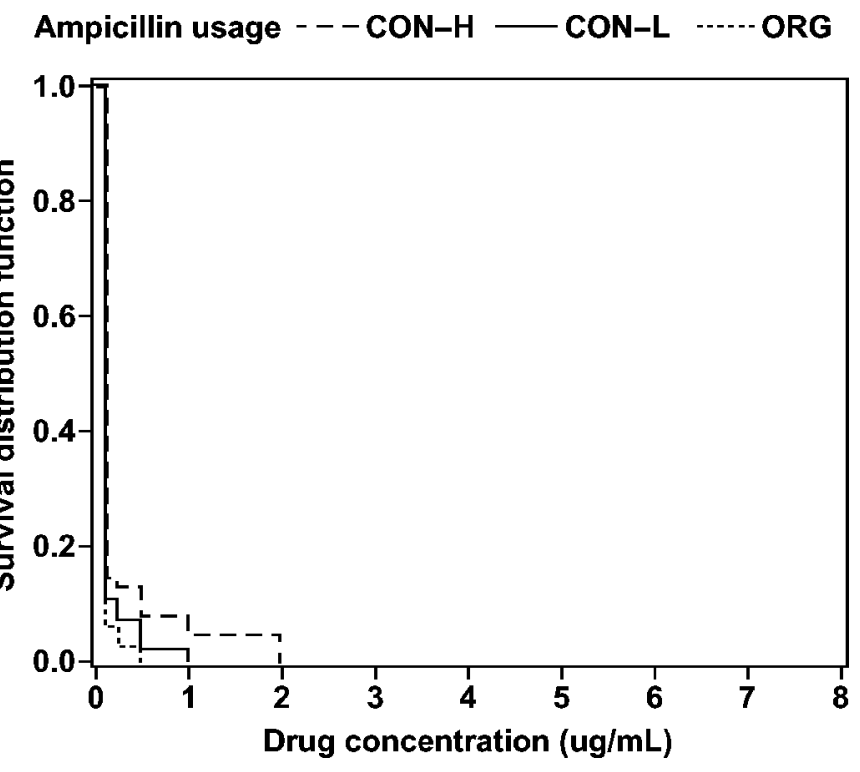

Figure 2. Kaplan-Meier plot showing survival proportion of 266 CNS isolates stratified on organic farms (ORG; $n=126$ ), no use of ampicillin or use less than or equal to the first quartile of usage (CON-L; $\mathrm{n}=80$ ) or ampicillin use greater than the first quartile of usage $(\mathrm{CON}-\mathrm{H} ; \mathrm{n}=60)$. Log-Rank test for equality of strata at higher minimum inhibitory concentration (MIC), $\chi^{2}=10.2, P=0.006$. Wilcoxon test for equality of strata at lower MIC, $\chi^{2}=4.1, P=0.126$.

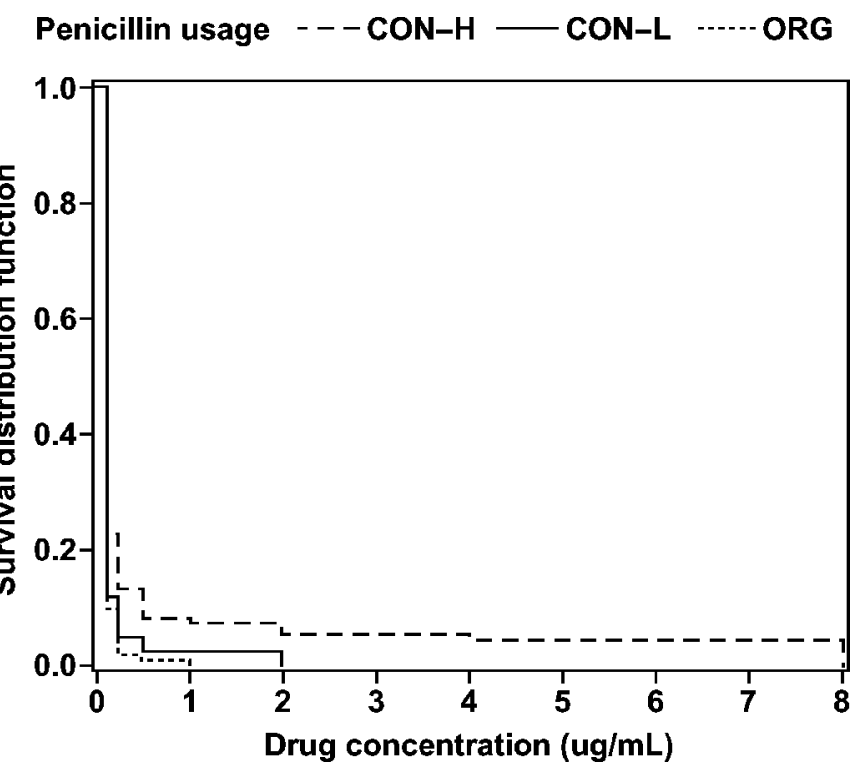

Figure 3. Kaplan-Meier plot showing survival proportion of 292 CNS isolates stratified on organic farms (ORG; $\mathrm{n}=134$ ), no use of penicillin or use less than or equal to the first quartile of usage (CON$\mathrm{L} ; \mathrm{n}=43$ ), or penicillin use greater than the first quartile of usage (CON-H; $n=115)$. Log-Rank test for equality of strata at higher MIC, $\chi^{2}=15.8, P=0.004$. Wilcoxon test for equality of strata at lower MIC, $\chi^{2}=9.7, P=0.007$.

sulfadimethoxine was greater for isolates obtained from ORG herds as compared with isolates obtained from CON herds. A large proportion of resistance of Strep. spp. to sulfadimethoxine was reported (Rossitto et al., 2002). Sulfonamides are occasionally used to treat mastitis in dairy cows, usually via a parenteral route for prevention of septicemia in animals infected with coliform mastitis. Two producers reported the illegal use of intramammary sulfonamides and it appears that more educational programming is necessary. Resistance to cephalothin was almost nonexistent as reported previously (DeOliveira et al., 2000; Rossitto et al., 2002). Our study failed to detect differences in cephalothin susceptibility based on herd type or usage groups. One possible explanation is that the lowest concentration (2 $\mu \mathrm{g} / \mathrm{mL}$ ) inhibited the majority of the isolates. Rossitto et al. (2002) used lower dilutions and reported much lower $\mathrm{MIC}_{90}$ for Staph. aureus $(0.25 \mu \mathrm{g} / \mathrm{mL})$ and Strep. spp. $(0.12$ to $1 \mu \mathrm{g} / \mathrm{mL})$. It is probable that the cephalothin concentrations used in the present study were too high to detect possible differences among groups.

Previous studies have described differences in susceptibility of isolates obtained from farms with different histories of potential exposure to antimicrobial drugs (Tikofsky et al., 2003; Rajala-Schultz et al., 2004). Tikofsky et al. (2003) used agar disk diffusion to study antimicrobial susceptibility of Staph. aureus isolated 
from cows on organic $(\mathrm{n}=144)$ and conventional herds ( $n=117$ ). Significantly fewer isolates obtained from conventional herds were susceptible to ampicillin, penicillin, or tetracycline compared with isolates obtained from organic herds. The conventional herds in that study used mainly amoxicillin and pirlimycin for treatments of clinical mastitis and penicillin/novobiocin for DCT; however, antimicrobial usage was not quantified.

Previous studies were not focused on quantifying exposure to antimicrobial drugs. Antimicrobial usage is not homogeneous among farms. Hoe and Ruegg (2006) reported recently that $12 \%$ of responders from very small farms $(<50$ cows $)$ reported no use of antimicrobial drugs, whereas none of the responders from large farms $(>200$ cows) reported no use of antimicrobial drugs. The current study was able to quantify the reported density of usage of antimicrobial drugs used for treatment of the most commonly reported diseases of dairy animals. Therefore, the antimicrobial usage groups of this study were defined objectively, rather than subjectively as reported previously.

The strength of an association between antimicrobial drugs and resistance is a causality guideline that is often measured by the use of odds ratio. The stronger the association, the more likely that the relationship is causal (Gordis, 2004). Some odds ratios calculated in this study showed strong associations between herd type and susceptibility status but others did not. A dose-response relationship between the antimicrobial exposure and resistance is another important causal criterion. Our study demonstrated a dose-response effect for several antimicrobial drug exposures and the MIC of the studied pathogens. To our knowledge, a dose-response effect for antimicrobial exposure and susceptibility outcomes of mastitis pathogens has not been described previously. An increasing number of studies have found a positive relationship between antimicrobial drug usage and resistance in dairy cattle, but consistency among studies is lacking because different methods were used to measure drug usage and resistance. Finally, a causal relationship is likely when cessation of exposure to antimicrobial drugs results in a reduction of the measures of resistance (Gordis, 2004), but this type of study is extremely difficult and expensive to conduct under commercial herd situations.

Our study did not detect a reduced risk of antimicrobial resistance in the farms that have been organic for a longer period compared with the farms that have been organic for a shorter period (data not shown). To fully evaluate causality it is important to consider alternate explanations (Gordis, 2004). Schwaber et al. (2004) hypothesized that the appropriate use of antimicrobial drugs should result in a reduction of the number of susceptible isolates within a population. Consequently, the proportion of resistant isolates would be increased and a higher proportion of resistant bacteria would be observed. The authors suggested that the rate of isolation of resistant pathogens would be better estimate of changes in resistance because rates introduce the concept of time.

In part of our statistical analysis, we used a number of $\chi^{2}$ tests to evaluate associations between herd type and the outcomes of susceptibility testing. These tests were performed using a $P$-value of 0.05 and it is possible that 1 or 2 of the observed relationships were spurious because of Type I error, but the results were generally consistent with the results of the survival analysis. Kaplan-Meier curves and survival analysis were used to study the relationship between antimicrobial drug usage groups and MIC. To our knowledge, this is a novel approach. In general, in survival analysis it is assumed that events may occur over a continuous scale, such as time. The MIC determined by broth microdilution is not a truly continuous variable because of the scale (doubling of dilutions). Therefore, it is not possible to conclude the exact shape of the survival curve. Yet, the use of this analysis allowed for comparisons of the survival function. The Log-Rank and the Wilcoxon statistics tested the hypothesis of homogeneity among curves of the different strata with different sensitivity at higher and lower concentrations of the antimicrobial respectively. An important feature of survival analysis is that censored data (i.e., those isolates that were not inhibited at the highest concentration) were included in the analysis. With other tests (ordinal $\chi^{2}$ ) those isolates should be removed from analysis, or included in a higher dilution that was not really tested and assumed that they were inhibited. Both situations are undesirable.

\section{CONCLUSIONS}

The relationships between reported antimicrobial usage and antimicrobial susceptibility in ORG and CON farms were studied. Use of 2 compounds commonly administered for treatment of IMI (penicillin and pirlimycin) was associated with resistance of mastitis pathogens, but use of many other commonly used compounds was not. A dose-response effect between pirlimycin usage groups and pirlimycin MIC was observed for all isolates studied. The use of penicillin was associated with reduced susceptibility of Staph. aureus and CNS isolates. However, the use of cephapirin (a widely used antimicrobial drug for IMI treatments) was not associated with reduced susceptibility of any of the studied pathogens.

Further studies should be designed to evaluate the temporal relationship of exposure and resistance, to 
analyze recovery rates of resistant pathogens, and the relative risks of the exposure groups.

\section{ACKNOWLEDGMENTS}

The authors gratefully acknowledge Y. H. Schukken for his advice on the use of survival analysis to study MIC distribution.

\section{REFERENCES}

Aarestrup, F. 2005. Veterinary drug usage and antimicrobial resistance in bacteria of animal origin. Basic. Clin. Pharmacol. Toxicol. 96:271-281.

Clinical and Laboratory Standards Institute (CLSI). 2002. Performance Standards for Antimicrobial Disk and Dilution Susceptibility Tests for Bacterial Isolated from Animals; Approved Standard. 2nd ed. CLSI, Wayne, PA. M31-A2.

Cox, L. A., and D. A. Popken. 2004. Quantifying human health risks from virginiamycin used in chickens. Risk Anal. 24:271-288.

De Oliveira, A. P., J. L. Watts, S. A. Salmon, and F. M. Aarestrup. 2000. Antimicrobial susceptibility of Staphylococcus aureus isolated from bovine mastitis in Europe and the United States. J. Dairy Sci. 83:855-862.

Erskine, R., J. Cullor, M. Schaellibaum, B. Yancey, and A. Zecconi. 2004. Bovine mastitis pathogens and trends in resistance to antibacterial drugs. Pages 400-414 in Natl. Mastitis Counc. Annu. Mtg. Proc., Charlotte, NC. Natl. Mastitis Counc., Inc., Madison, WI.

FDA-Center of Veterinary Medicine. 2004. FDA-approved animal drug products online database system. Online. http:// dil.vetmed.vt.edu/ Accessed Nov. 11, 2005.

Gordis, L. 2004. Epidemiology. 3rd ed. Elsevier, Philadelphia, PA.

Gruet, P., P. Maincentb, X. Berthelotc, and V. Kaltsatosa. 2001. Bovine mastitis and intramammary drug delivery: Review and perspectives. Adv. Drug Deliv. Rev. 50:245-259.
Hoe, F. G. H., and P. L. Ruegg. 2006. Opinions and practices of Wisconsin dairy producers about biosecurity and animal wellbeing. J. Dairy Sci. 89:2297-2308.

National Mastitis Council. 1999. Laboratory Handbook on Bovine Mastitis. National Mastitis Council, Madison, WI.

Pol, M., and P. L. Ruegg. 2007. Treatment practices and quantification of antimicrobial drug usage in conventional and organic dairy farms in Wisconsin. J. Dairy Sci. 90:249-261.

Prescott, J. F., J. Desmond Baggot, and R. D. Walker. 2000. Antimicrobial Therapy in Veterinary Medicine. 3rd ed. Iowa State University Press, Ames.

Rajala-Schultz, P. J., K. L. Smith, J. S. Hogan, and B. C. Love. 2004. Antimicrobial susceptibility of mastitis pathogens from first lactation and older cows. Vet. Microbiol. 102:33-42.

Rossitto, P. V., L. Ruiz, Y. Kikuchi, K. Glenn, K. Luiz, J. L. Watts, and J. S. Cullor. 2002. Antibiotic susceptibility patterns for environmental streptococci isolated from bovine mastitis in Central California dairies. J. Dairy Sci. 85:132-138.

SAS Institute. 2003. SAS/STAT User's Guide. Version 9.1. SAS Inst., Inc., Cary, NC.

Sawant, A. A., L. M. Sordillo, and B. M. Jayarao. 2005. A survey on antibiotic usage in dairy herds in Pennsylvania. J. Dairy Sci. 88:2991-2999.

Schwaber, M. J., T. De-Medina, and Y. Carmeli. 2004. Epidemiological interpretation of antibiotic resistance studies - What are we missing? Nature Rev. 2:979-983.

Smith, A., F. K. Neave, and F. H. Dodd. 1966. Methods of reducing the incidence of udder infection in dry cows. Vet. Rec. 79:233-236.

Tikofsky, L. L., J. W. Barlow, C. Santisteban, and Y. H. Schukken. 2003. A comparison of antimicrobial susceptibility patterns for Staphylococcus aureus in organic and conventional dairy herds. Microb. Drug Resist. 9:39-45.

USDA National Organic Program. 2002. Online: http://www.ams.usda.gov/nop/NOP/standards.html Accessed Nov. 15, 2005.

Yan, S. S., and J. M. Gilbert. 2004. Antimicrobial drug delivery in food animals and microbial food safety concerns: An overview of in vitro and in vivo factors potentially affecting the animal gut microflora. Adv. Drug Deliv. Rev. 56:1497-1521.

Zwald, A. G., P. L. Ruegg, J. B. Kaneene, L. D. Warnick, S. J. Wells, C. Fossler, and L. W. Halbert. 2004. Management practices and reported antimicrobial usage on conventional and organic dairy farms. J. Dairy Sci. 87:191-201. 